$T$ here's an old joke about the farmer who responds to a driver's request for directions: 'I wouldn't start from here'. For women beating a path to a leading position in science, 'here' would include Bulgaria, Croatia, Cyprus, the Czech Republic, Estonia, France, Greece, Hungary, Israel, Italy, Latvia, Lithuania, Luxembourg, Malta, Poland, Portugal, the Slovak Republic, Slovenia and Turkey.

These countries are characterized in a report from the European Commission (EC) as being relatively inactive in national and institutional policies intended to overcome the obstacles faced by women in their scientific careers. More positively, the document details ways in which many of the main funding agencies across Europe are trying to improve matters.

The Gender Challenge in Research Funding (see http://tinyurl. com/ecgender) was written by a 17-strong expert group chaired by a woman and containing five men. That male minority is an inversion of the usual pervasive and regrettable imbalance of the sexes in European peer-review structures. Only in those countries that have been most proactive in supporting women's careers - Finland, Sweden and Norway - do women constitute more than $40 \%$ of 'gatekeeper' scientific boards, according to 2004 data, the latest available, quoted in the report.

Many leading funders are trying to do better. Germany's DFG, for example, has set equal opportunities as a statutory objective since 2002 , with working groups targeting the various factors that undermine that goal. But Germany's overall performance is depressing for its women - and for its men too, who presumably want to see the country make good use of its talent. Between 1999 and 2004, the proportion of women acting as peer reviewers for the DFG rose - from $6 \%$ to $9 \%$. Of all European Union countries, Germany has the lowest representation of women in the highest academic positions, despite an equal representation of men and women as graduates.

\section{Can coal be clean?}

\section{New money must provide stimulus to get carbon capture and storage up and running.}

7 here is good news about carbon capture and storage (CCS), the technology that is intended to slow global warming by capturing industrial carbon dioxide emissions and injecting them underground. Last week, US energy secretary Steven Chu outlined plans for using some $\$ 2.4$ billion in economic stimulus money to research aspects of CCS. These efforts will join important research already under way. Several European nations are looking at technical issues in partnership with industry; Australia has a cutting-edge research programme; China has entered the game; and the United States has a number of existing pilot projects across the country.
The pressures on women who want to excel in science are acute everywhere. This is particularly true for mothers of young children who, even in the most progressive countries, are generally expected to take on most of the responsibility for home and family while still being expected to write proposals, publish papers and spend long hours in the lab. Added to that is the committee work. Ironically, being a member of a minority that is targeted for positive action can lead to endless requests for advice and involvement, which cut even further into research time.

Many of these pressures will ease only when fathers regard themselves as having equal responsibility for parenting. But employers also have a responsibility to assist parents. Another report published last week by the EC, Women in Science and Technology - Creating Sustainable Careers (http://tinyurl.com/womensci), highlights the ways in which Europe's employ-
"The pressures on women who want to excel in science are acute everywhere." ers provide support. These include such prosaic but essential initiatives as ensuring that important meetings are timed to allow parents to leave the office as necessary, and not overlooking those who work part-time when it comes to assigning senior responsibilities.

According to the report, the Netherlands is a notable hotspot for promoting women's interests. Over the past ten years, the funding agency NWO has given Dutch universities incentives to award senior lectureships and professorships to high-achieving women, without branding them as tokens.

Such collaboration, perhaps with sticks as well as carrots, between funding agencies and the institutions they fund, is essential if robust change is to come more rapidly. Without it, Europe will continue to include far too few countries that, for ambitious women scientists, are good places from which to start.

Unfortunately, none of the current work translates into the rapid deployment required to prove this technology in the commercial arena. The different CCS technologies need to be demonstrated on power plants new and old, and industry must show that the $\mathrm{CO}_{2}$, once injected into old oil and gas fields or saline aquifers, will stay put. Although Australia, China and Britain are working on such demonstrations, there is widespread agreement that many more are needed. Last year, the G8 leaders rightly called for upwards of 20 demonstration projects around the globe. Without that kind of commitment, no one will ever know what the true potential of CCS could be.

Chu seems to recognize the problem. The energy department is in talks to restart the United States' flagship CCS project FutureGen, a projected coal-fired power plant that would capture $\mathrm{CO}_{2}$ and store it underground. The Bush administration shut down FutureGen last year after a dispute over rising costs, signalling to the rest of the world 